\title{
Design as Research in Landscape Architecture $\odot$
}

\author{
Steffen Nijhuis and Jeroen de Vries
}

ABSTRACT Research through design (RTD) is a frequently used concept in the daily practice of education and research in the field of landscape architecture. RTD as a concept usually refers to a research method in which spatial design plays the leading role. The underlying premise is that design is a form of research and involves a culture of thought. There is a dearth of literature addressing the act of design as a research process in the field of landscape architecture. This article contributes to the discourse by addressing how spatial design can be applied as a research strategy. We define design as a form of research and identify how design relates to other more conventional definitions of research methods. We elaborate on RTD as a concept and the types of knowledge that it generates. The article also addresses the design process and design methods in landscape architecture. Criteria for accepted, responsible research are translated into practical requirements that can guide RTD processes in academic and professional contexts. To continue developing landscape architecture as a design discipline, it is important that the theoretical, methodological, and technical foundations of spatial design are clarified and strengthened.

KEYWORDS Research through design, research by design, spatial design, research methods, knowledge acquisition

\footnotetext{
(2) This open-access article is distributed under the terms of the CC-BY-NC-ND license (http://creativecommons.org/ licenses/by-nc-nd/4.0) and is freely available online at http://lj.uwpress.org
}

\section{INTRODUCTION}

In the landscape architecture field and its related disciplines, spatial design is a core activity oriented toward generating solutions for urban and rural areas and project sites such as parks, gardens, and squares, or exploiting potentials by creating conditions for spatial, ecological, and social developments. Spatial design is equivalent to the combined operation of conceptual and schematic design (as opposed to detailed design). "Conceptual design" refers to the expression of idealized spatial relationships among design program components. Schematic design refers to real spatial relationships in the biophysical context of the landscape being designed (i.e., fitting the design concept to the biophysical reality of the landscape). In landscape architecture education and research in the academic context, as well as in practice, spatial design is increasingly used and acknowledged as a form of research, often referred to as "research by design" or "research through design(ing)" (Steenbergen et al., 2002, 2008; Nijhuis \& Bobbink, 2012; Groat \& Wang, 2013; Lenzholzer et al., 2017). For the sake of clarity, the term "research through design" (RTD) is consistently used throughout this article.

RTD often refers to a particular heuristic (way of knowing) or research strategy in landscape architecture (Steenbergen et al., 2002; Deming \& Swaffield, 2011). In this context, "strategy" refers to working in a well-considered manner to achieve a particular goal or to address a research question. The central position is that design can be considered a research strategy or a culture of thinking, as put forward by Schön (1983), Zeisel (2006), and Cross (2007). This implies that making the original creative work is at the center of the inquiry (Carruth, 2015). The implication assumes that through design 
explorations, research questions can be answered related to the possible shape of urban, peri-urban, or rural landscapes, as well as how changes in the built environment can be designed or guided while using social or ecological processes.

RTD can be used to identify what users and stakeholders think about future developments. Positioning ideas, programs, and demands in outdoor space makes it possible to discover the possibilities, limitations, and questions that call for further exploration. During a design process, each spatial choice implies a decision with each mark drawn, each function allocated, each choice of materials, and so on. Sometimes there is an assumption about the conditions. In others, the choice is relative to an alternative, and in still others, it is an assumption about how the design will be experienced by its users or even an assessment of how it will influence the ecology or the spatial environment's quality. It is therefore important to articulate design decisions. This is usually accomplished with a comment about or on the design sketch, or in a blog associated with the design.

Can spatial design be regarded as a research strategy? If yes, what makes design an exploratory activity, and what are its requirements? Extensive literature exists on the relationship between research and design in landscape architecture (Chenoweth \& Chidister, 1982; Armstrong, 1999; LaGro, 1999; Milburn et al., 2001; Gobster et al., 2010; Deming \& Swaffield, 2011; Thering \& Chanse, 2011; Murphy, 2016; Lenzholzer et al., 2017). There are fundamental attempts that elaborate on designrelated research strategies, combining research and design in a consistent and systematic way (Steinitz, 1990; Milburn \& Brown, 2003; Nassauer \& Opdam, 2008; Nijhuis \& Bobbink, 2012). A survey by Lenzholzer et al. (2018) points out that many RTD studies and publications misuse the term "research" rather frequently. There is also a dearth of literature in landscape architecture addressing itself as a research process. As a reflexive research strategy, Deming \& Swaffield (2011, p. 205) refer to it as "projective design" and point to criteria for RTD that elaborate on design operations, but does not provide a full overview on the explorative mechanisms behind it.

This article contributes to the RTD discourse by providing an overview on design as research strategy while addressing (1) how spatial design can be regarded as research, (2) what kind of knowledge it produces and (3) what important conditions to this end are needed. It builds on the existing literature to promote the advancement of landscape architecture as a design discipline. To continue developing as an academic field, the theoretical, methodological, and technical foundations of spatial design must be clarified and strengthened (Van den Brink \& Bruns, 2014). In addition, to facilitate RTD processes in academic and professional contexts, criteria for development of accepted and responsible research endeavors must be translated into practical guidelines.

This article follows in several sections. The first section addresses design as an exploratory activity and explains how designing relates to other research methods. Then the concept of RTD is clarified along with the types of knowledge it generates. This is followed by an elaboration of a design process and design methods. Finally, criteria for accepted, responsible research are translated into minimum and practical requirements that RTD should unequivocally demonstrate.

\section{DESIGN AS EXPLORATORY ACTIVITY IN LANDSCAPE ARCHITECTURE}

Steinitz (1995) and Glanville (2015) differentiate between "design" as a noun and "design" as a verb. As a noun, design is the outcome of the design process in which a product (that is, the design) is projected and sometimes also implemented. "Design" as a verb means the act of projecting future environments or objects, for instance, through drawings or other representations. In landscape architecture the verb "design" means giving four-dimensional form and function to landscapes at multiple geographic scales and developing landscapes in time. The scale, natural, and societal context and the resulting complexity of landscape architectural designs are different from other design disciplines, such as industrial design or interior design. This article views design as an exploratory activity that produces knowledge that meets a research goal or answers a (set of) research question(s). Here, design exploration equals research inquiry. However, this also implies that not every design activity can or should be considered a research inquiry focused on discovery. 


\section{Production of Knowledge}

Exploration implies searching for knowledge. In principle, exploration involves the production of new knowledge, not the reproduction of existing knowledge (as is the case with studying, information gathering, or literature review). The search for knowledge can take place in a deliberate or nondeliberative manner. Exploration is understood as a targeted research activity, meaning that there is a plan describing what is being investigated and why, there are clear goals (for example, research questions), and that the means for achievement (how and where) have been determined. From this perspective, exploration is a purposeful and systematic search for new knowledge in the form of answers to questions (Verschuren, 2007). This search is cast in the context of solving questions that are particular to a certain set of land use issues in specific social-ecological and temporal contexts. In other words, design inquiry and its findings are idiosyncratic to a specific problem in a specific place at a specific time. Results and inferences of the inquiry (i.e., answers to the questions) are circumscribed by the problem set that drove pursuit of the inquiry and the place and time wherein the inquiry was performed. Methodical action is a central theme. In addition to being an efficient way of achieving goals, it is also an important precondition for ensuring that others will recognize the knowledge acquired. A method exists when the following are present: (1) a conscious deed, (2) a systematic search process, and (3) questions with corresponding answers (Van Schilfgaarde, 1970). Although spatial design is usually a conscious deed, it is far from always a systematic search process in which particular questions are answered. In many cases, design is used to solve a problem or provide a plan for future change. How can design be seen as a research strategy? To answer this question, it is important to discuss the acquisition of knowledge and the background of the connection between design and research.

\section{Worldviews and the Acquisition of Knowledge}

There are four paradigmatic worldviews, or cohesive sets of models and theories, for the scientifically sound acquisition of knowledge (Creswell, 2009). These include:
- Positivism (or postpositivism), in which knowledge is developed and tested through experimentation and observations using empirical methods. The ability to provide principally quantitative support is an important underlying dimension in this worldview.

- Social-constructivism, wherein knowledge is shaped through logical reasoning in a given social and political context. Qualitative research methods play an important role in this context.

- Participatory/advocacy. Here the research inquiry is intertwined with politics and a political agenda that contains actions that may change the lives of participants, the related institutions, and the life of the researcher. Quantitative and qualitative methods can also be used in conjunction with each other (Creswell \& Creswell, 2018; Creswell \& Plano Clark, 2018).

- Pragmatism, a perspective in which different knowledge acquisition methods (e.g., experimentation, observation, modeling) are combined in a practical way. In this worldview, there are several ways of producing valid knowledge.

Lenzholzer et al. (2017) argue that design can relate to any of these worldviews. Given that the research conducted in the field of landscape architecture is always contextual, as well as application-oriented and interdisciplinary, the most obvious way to acquire knowledge is in the context of pragmatism, also referred to as mode- 2 knowledge production (Gibbons et al., 2012; Nowotny et al., 2013). Using pragmatism is fundamentally different from what is customary in natural or social sciences, in which quantitative or qualitative methods are used. In pragmatism, possible methods are combined to synergize practical-productive knowledge in a process that integrates understandings from thinking (academic scholarship), creating (artisanry), and acting (practical wisdom) (de Jonge, 2009).

Practical-productive knowledge can be brought into practice in some manner. In this context, the fundamental question concerning the knowledge that has been acquired does not concern whether it 
is true but whether it "works within the objective" (Klaasen, 2004). This does not mean that such research inquiry is subject to fewer or no requirements, which will be addressed.

\section{Design as a Systematic Search}

Design can be a powerful method for generating practical-productive knowledge by individuals or groups (Zeisel, 1981; Schön, 1983; Cross, 2007). In this process, spatial design is deliberately applied in a systematic search for possible solutions to a practical problem. Design is not merely a form of problem solving. "Problem" not only refers to a challenge, it can also refer to the potential of an area for development in a certain direction. "Design devises courses of action aimed at changing existing situations into preferred ones" (Simon, 1981, p. 129). Simon (1981) suggests that design is concerned with how things ought to be with devising artifacts (the design) to attain goals. According to this understanding, design is a means to achieve goals and not the goal itself.

Design as research inquiry refers to a process of action dominated by verbs such as "finding," "producing," and "translating” (Hamel, 1990). As an action, design involves structuring thought through a creative process involving the interaction of reason and emotion while focusing on visual thinking and communication (Foqué, 1975). "Structuring" refers to the intuitive or rationally supported spatial translation or transformation of conceptual, contextual, or programmatic properties. The conscious or unconscious synthesis that emerges through this process is precipitated into a visual form through drawing, charting, or modeling involving the use of analogue or digital media. Visual thinking is essential to generating knowledge and ideas through creating, inspecting, and interpreting representations that have not previously been visible. Visual communication entails the effective transfer of ideas into visual form. Given these specific properties, design is an intellectual tool for structured thinking and action aimed at acquiring practical-productive knowledge. This approach is referred to as RTD.

\section{RESEARCH THROUGH DESIGN}

Research and design can relate to each other in at least four distinct manners:
- Research for design. Research is used to inform or validate the design. In other words, knowledge acquired in a targeted manner becomes input for the design. This is the most common relationship between design and research.

- Research on design. Plan analyses are used to study and organize operational design. It involves finding specific design concepts, principles, precedents, or types as a foundation for future design. This is also known as design research.

- Research through design. A form of research where designing and designs are applied as a research strategy. RTD explores, identifies, and maps possibilities. This process often informs alternative concepts and ideas.

- Research about design. This primarily concerns understanding and identifying design processes through observations, interviews, and other activities of designers. It yields important starting points for design didactics or other purposes, such as specifying the principles of the RTD process.

In practice, combinations of these types are often applied. For example, Nijhuis \& Bobbink (2012) present an example of an approach in which research on and through design are described in a cohesive process, where landscape architectonic typologies and design principles derived from multiple case studies serve as a basis for design experiments. In this article, the focus is on RTD, a particular search process that uses design as a means to produce practical-productive knowledge.

RTD as a research inquiry is different from scientific research (science), where reality is defined by means of explanatory models. It also varies from artistic inquiry (art), wherein reality is questioned by means of expressing conceptual models (Lee, 2011). The objective of design exploration is to produce practical-productive knowledge that enhances or at least changes reality (virtually or literally) by means of exploratory models. Such models combine the mechanisms of research and design.

Research, per se, is aimed primarily at discovery-acquiring knowledge and exposing existing facts. A large amount of research is deductive and 
Figure 1

RTD does not consist solely of design but includes a systematic search for the most effective and efficient solution to the problem that has been posed. During this search, following principles of abductive logic, the problem and the objective can be refined or changed. (Adapted from Kalay, 2004.)
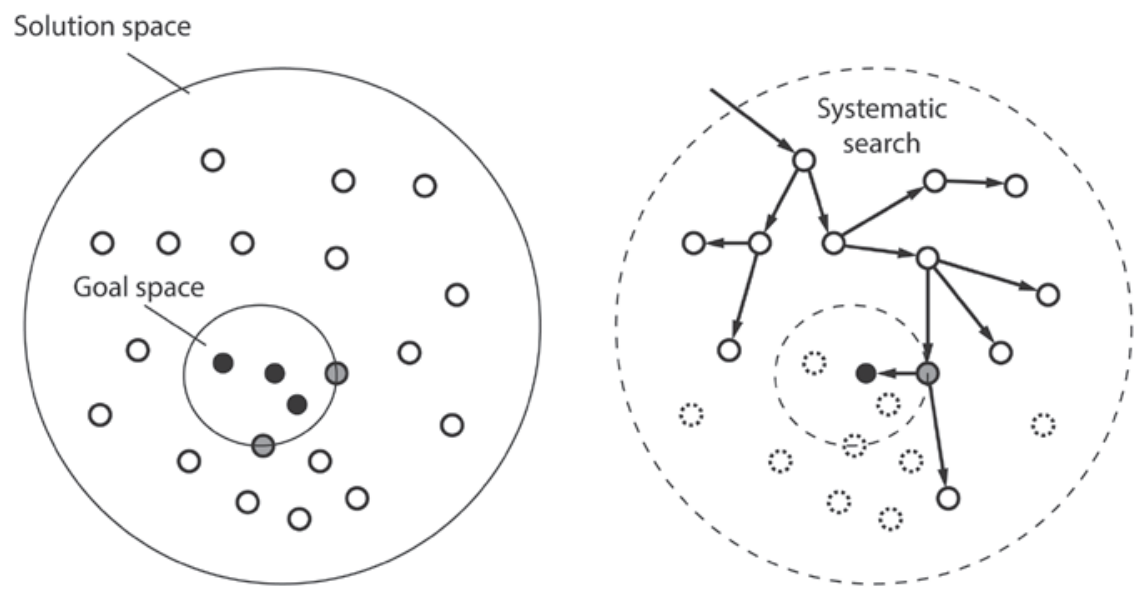

takes place by generating a certain idea or proposition (hypothesis) and establishing evidence to support or refute the hypothesis (from hypothesis to proof, which implies evaluation of hypotheses by means of evidence). Inductive research begins with specific observations of a single example and proceeds through analysis to broader generalizations and theories based on these observations (from observation to knowledge, which implies hypotheses based on evidence).

Design aims toward invention-that is, finding spatial solutions and "making them possible." Design also involves abduction, wherein hypotheses are simultaneously generated and evaluated in a reflexive process. The hypothesis is adjusted according to observations and vice versa (Pierce, 1955; Magnani, 2001). The most effective solution emerges by weighing various abductions in terms of possibility and probability (although there may be other solutions). In many cases, multiple solutions exist for the same problem. The search for solutions can take place within a setting in which the research object and the context have been determined, thereby yielding specific knowledge (e.g., how a particular problem can be solved in a particular context). It is also possible to create generic knowledge in the form of typologies or principles by disconnecting the solutions from the context and evaluating their general validity.

In RTD, the mechanisms of research and design are combined methodically, thereby allowing the acquisition of specific and generic knowledge, primarily through abduction. Specific knowledge is applicable to a particular situation or a particular context, and generic knowledge is more generally applicable.

\section{Dealing with Complexity}

RTD is a suitable method for solving complex problems that are also referred to as ill-defined or wicked problems (Rittel \& Webber, 1973; Rowe, 1998). Such problems are complex, uncertain, and have multiple explanations. In many cases, the exact problem is not clear in advance. Design-conceiving of a spatial solution-can help one further define problems and search for integrated solutions. The researcher-designer answers knowledge questions by visualizing/representing spatial solutions using methods related to drawing or modeling. During a design process, designers make decisions based on specialized knowledge, the context, and the situation. The created design (usually in the form of a design sketch with accompanying cross sections or three-dimensional models) and with the arguments underlying the choices generate knowledge that can lead to an answer to the research question. RTD is not so much about the actual design as it is about the use of design thinking to solve problems. RTD thus involves more than simply creating a design; it is a systematic search for answers in which possible solutions are made explicit (Figure 1).

\section{Design as a Process of Discovery and Invention}

Three phases are distinguishable in the search associated with a design process: analysis, synthesis, and evaluation. These phases are interconnected and 


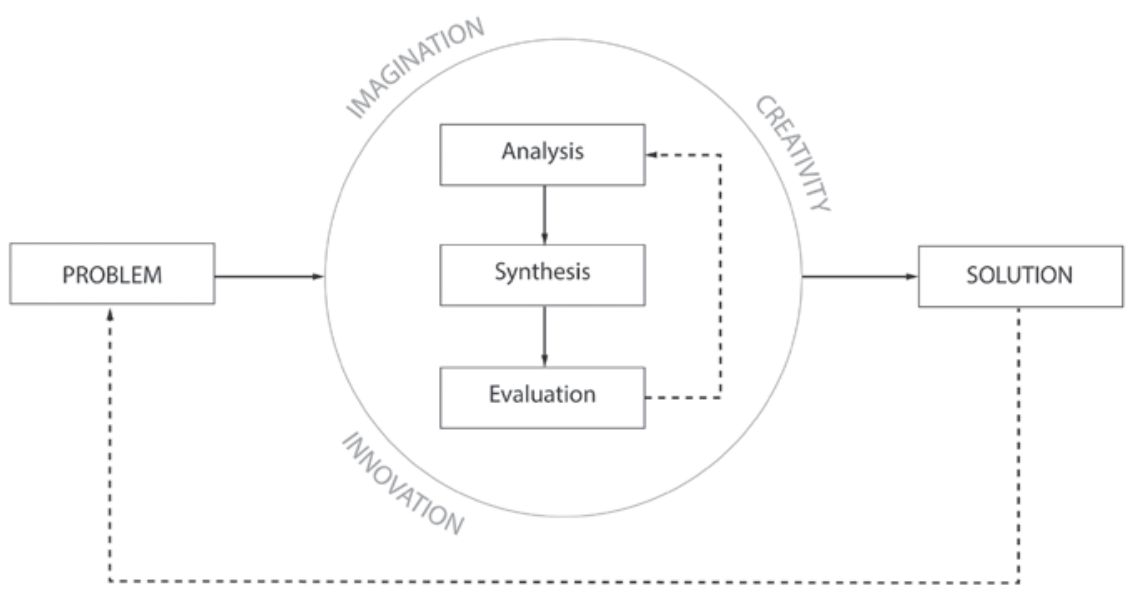

Figure 2

Design as a dialogue between a problem and a solution through analysis, synthesis, and evaluation. Imagination, creativity, and innovation play important roles in this process. (Drawing: Steffen Nijhuis.) cannot be regarded separately (Foqué, 1975; Schön, 1983; Jones, 1992; Roozenburg \& Eekels, 1996; Lawson, 2008). In RTD, these phases are preceded by a design problem (that is, the objective) statement and are concluded with a design solution. Beginning with a clearly founded objective enables the search to be conducted in a targeted manner, with knowledge of that being sought.

The analysis phase involves collecting and interpreting information. It seeks an enhanced understanding of the context of the design and identifying viable possibilities.

In the synthesis phase, partial solutions are developed and brought together as resolutions for the problem as a whole. Synthesis entails a cycle of emergence and development. Emergence involves the creative translation of latent, half-formed internal imaginations in the mind of the designer within an "embryonic" design model, in which initial ideas take on a tentative shape based on an intuitive idea or the concept developed during the analysis phase. This is also known as incubation and illumination. The development cycle concerns the further refinement of the initial idea, thereby achieving a greater extent of completeness, coherence, and specificity.

The evaluation phase entails assessing integral solutions according to the objective and the identification of alternative problem solutions.

These phases occur in an iterative process, in which the objective and the alternative solutions can be further refined. For example, a designer can start with a design solution that must subsequently be supported by a better-defined objective. Then the design may refine this objective. The design process is not linear. Rather, it consists of several cycles of feedback. RTD can thus be understood as a dialogue between a problem and a solution through comprehension, analysis, synthesis, and evaluation (Figure 2).

Imagination, creativity, and innovation play important roles in all phases of a design process (Von Seggern et al., 2008; Robinson, 2013). Imagination is the process of bringing to mind things that are not yet available to our senses. Creativity is the process of developing original and valuable ideas; innovation is the process of converting new ideas into practice. The combination of these three elements and their usage make design a powerful heuristic research strategy in which the content evolves from action (Foqué, 1975; Zeisel, 1981; Schön, 1983) (Figure 3). In search of a design solution, the process is targeted. As the search unfolds, the solution is constantly adjusted by the process of design. Idea generation begets its representation in draft form, which is then evaluated according to original design goals. In turn, evaluative feedback generates new ideas. This interaction yields new knowledge whose production can be documented.

The research process is reflective, with analytic thinking and design thinking going hand in hand (Figure 4). In this context, analytical thinking aims at data translation and interpretation into knowledge (discovery), and design thinking aims at the development of new knowledge through synthesis and spatial translation (invention). Given this interaction, visual representations (e.g., drawing 
Figure 3

Ideas are formed, presented, and tested in a cyclical process through which the design develops. (Adapted from Zeisel, 1981.)

\section{Figure 4}

Analytical thinking is aimed at translating and interpreting data into knowledge (discovery), and design thinking is aimed at developing new knowledge through synthesis and spatial translation (invention). (Source: After Nijhuis, 2015).
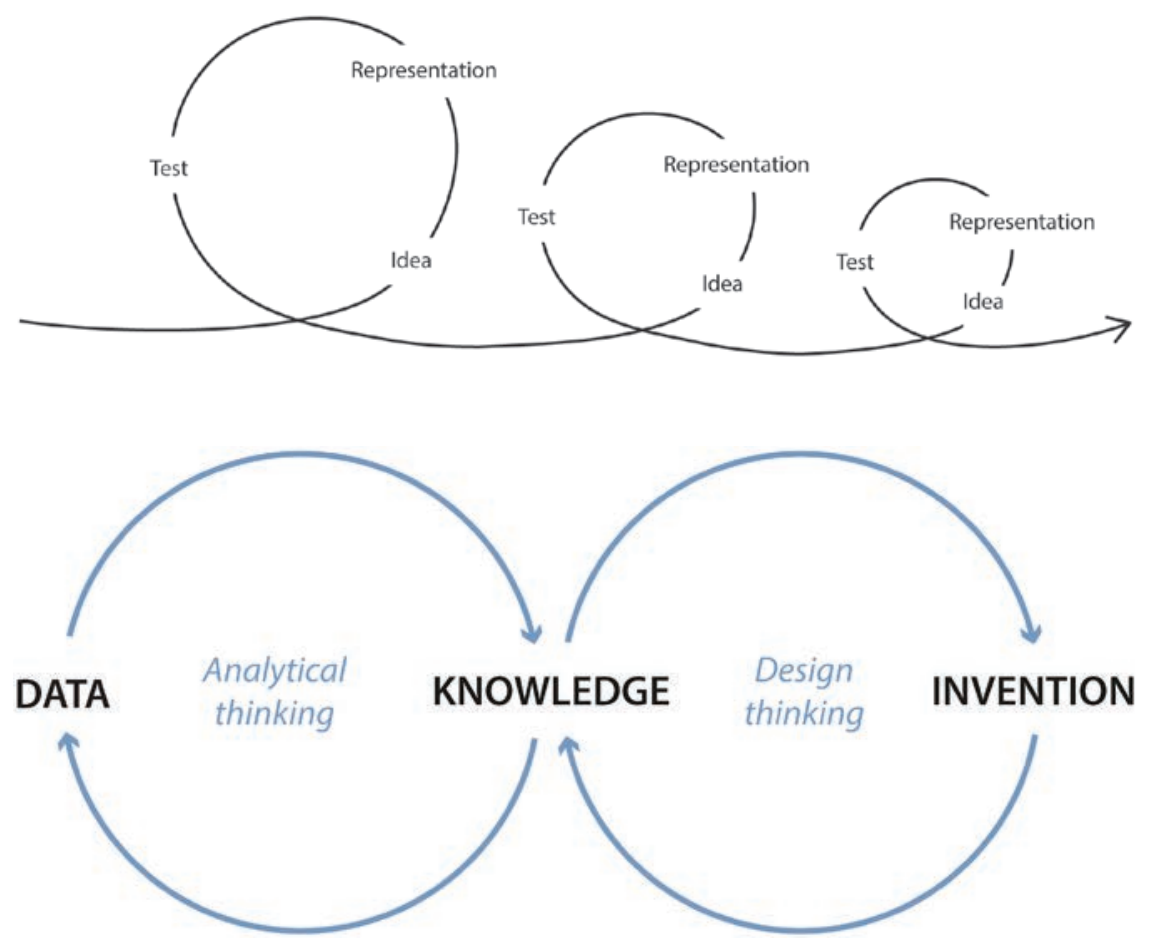

and models) are not by-products. Rather, they play a central role in the process of thought production and representation.

\section{The Role of Visual Representations}

In any RTD process, visual representations (including maps, blueprints, or scale models, as well as text, still images, and moving images) are important tools (Figure 5). Advancements in recent decades added digital media and new media to this list. $\mathrm{Vi}$ sual representations transfer information or knowledge through images, text, speech, and sound using digital technology. Examples include the use of computers, internet, virtual 3D landscapes, digital video and photography, computer graphics, geographic information systems (GIS), computer simulations, computer-aided drafting, virtual reality, and mobile telephony. Like digital media, social media are online platforms on which users provide content. Examples include blogs, web forums, and social networks. Whether digital or analogue, these media are instruments with which to investigate, design, and communicate (Nijhuis, 2013) (Figure 6).

Exploration and design emphasize thinking and reflection, while communication focuses on the effective transmission of specific information and knowledge. Deliberation, processing, documenting, learning, fabricating, testing, associating, speaking for, and working in groups are all activities in which these instruments are used. For example, virtual 3D landscapes are built and assessed by residents to examine their amenity and usage values. For hydrological issues, creation of a water cycle scale model enables testing the effect of the current or developing a calculation model. In the effective transmission of results, it is wise to combine various forms of visual representation. An effective way to communicate is by working with maps, three-dimensional drawings, cross sections, and mood images accompanied by comments and keywords. The combination of drawings and text makes a design intelligible to third parties.

An example of a method that tightly couples the creation of design proposals with GIS-based impact simulations is the geodesign framework as developed by Steinitz (2012). Geodesign as such is made up of a set of geo-information technologydriven methods and techniques for planning built and natural environments in an integrated process, and it includes project conceptualization, analysis, design specification, stakeholder participation, and collaboration. 


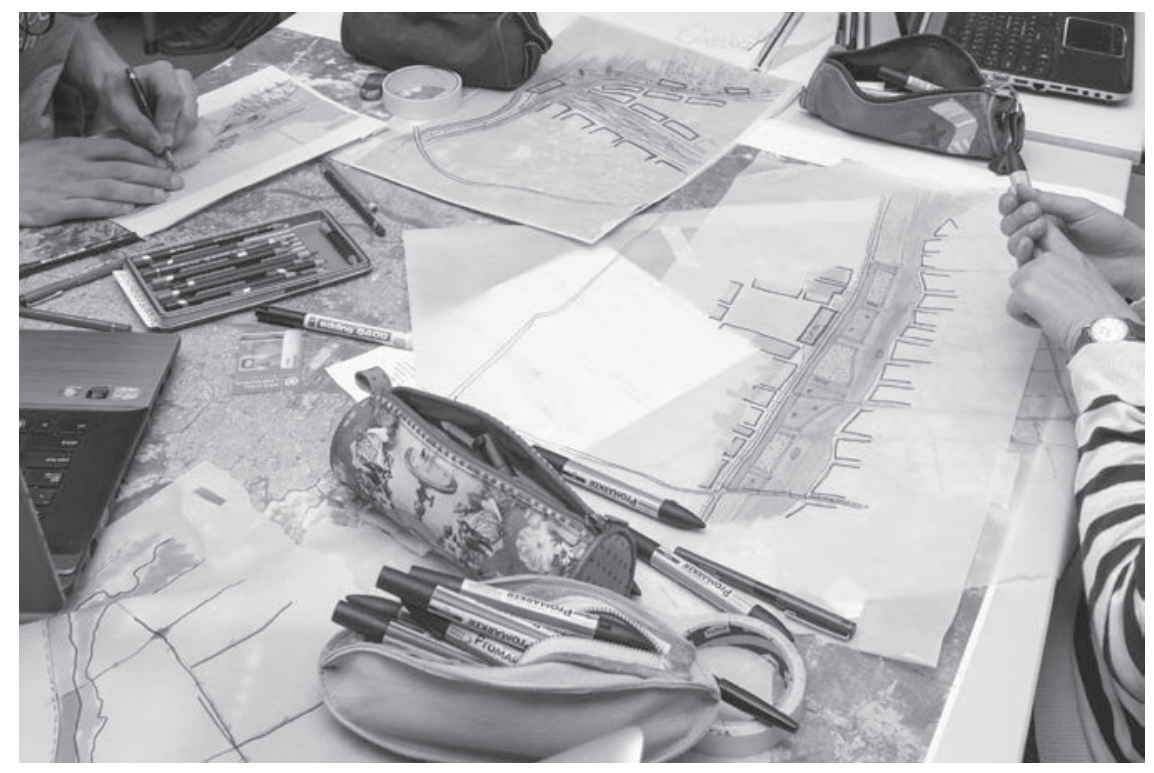

Figure 5

Pen and paper are often used in RTD processes. (Photograph: Ben ter Mull.)

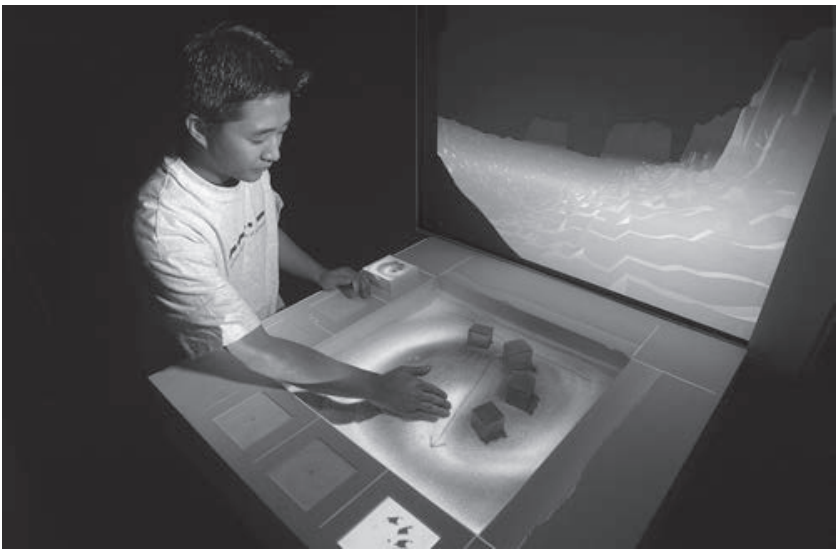

\section{RTD AND KNOWLEDGE PRODUCTION}

In RTD, landscape architects apply intellectual and design abilities to projects and the idea formation. The design process blends this knowledge with designing and idea formation. Information from related fields (e.g., civil engineering, agriculture, urban planning, environmental psychology, ecology) is spatially referenced and integrated. The knowledge of relevant laws and policies in the context of the design are spatially referenced and incorporated into spatial choices. In this process, designers think across multiple scales: element, place, neighborhood, community, city, area, region, and world. Designers develop representations of probable and alternative futures, search for new spatial solutions, and test the consequences of spatial design choices.
Figure 6

Tangible user interfaces will become increasingly important to designers. The interaction between humans and computers plays a central role in this regard. Such intuitive interfaces provide a quick interaction between interventions and their effects, like in a virtual prototyping feedback loop. In this case, the designer literally shapes the landscape by distorting "three-dimensional clay or sand." At the same time, the properties of the formed landscape (e.g., contour lines, water drainage, and angle of inclination) are visualized on adjoining screens. (Image courtesy of Carlo Ratti, MIT Media Lab, Tangible Media Group, 2002.)

The following are important knowledge elements of spatial design:

- Creating sustainable solutions, with particular attention to criteria relating to water management, ecology and biodiversity, climate resiliency, energy, quality of life, and social engagement.

- The structure and development of the outdoor space.

- The meaning and usage possibilities of the outdoor space for individuals and society.

- Natural processes and ecology that affect the character of outdoor space: soil, water, climate, flora, and fauna.

- Civil engineering design and implementing technical components of the outdoor space. 

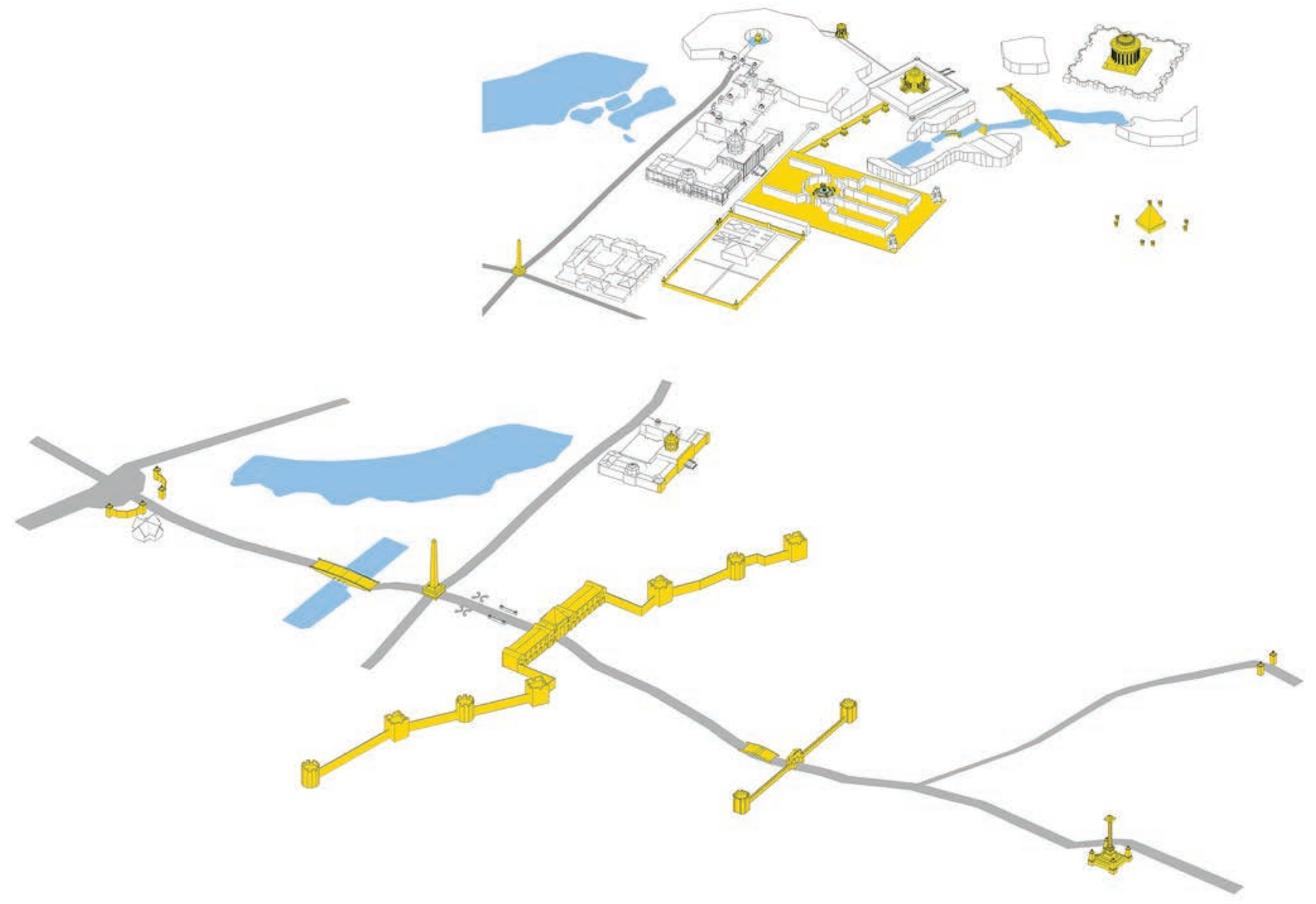

Figure 7

Typological research exploration as a foundation for a new design. (Source: Steenbergen et al., 2008).

The power of RTD is that it provides an integrated means of developing answers to questions, including a way of weighting the relative values of various aspects (e.g., spatial structure, ecology, social meaning, usage, sustainability, and future value). The investigation focuses on how a landscape could function in the future and on how it currently functions. In this context, it considers the range of alternative solutions that might be possible. But how does this relate to different RTD approaches?

\section{Approaches to RTD}

A design approach is a system for guiding, facilitating, and informing a design process. Several design approaches can be applied for RTD. Many methods developed in landscape architecture are more or less rational or intuitive, exploratory, or assessmentfocused. For example, various approaches guide question exploration, bring the designer's intuition explicitly into view, and support a systematic design (Foqué, 1975; Westrik \& Büchi, 1989; Jones, 1992; Martin \& Hanington, 2012; Boeijen et al., 2014). The common factor is that design is applied in a methodical manner to produce knowledge. Three categories of RTD approaches in landscape architecture exist:

- Design approaches that focus on concept. These approaches center on a form, type, or model. Form concepts are often intuitive or associative (e.g., direct analogy or symbolic analogy), and they can be used to guide a design process (e.g., biomimicry). Types or typologies refer to the reproducible cohesion of design tools (Figure 7), types of spatial relationships (e.g., landscape type), or pattern language (Alexander et al., 1977), and they are often used as a foundation for the design. 


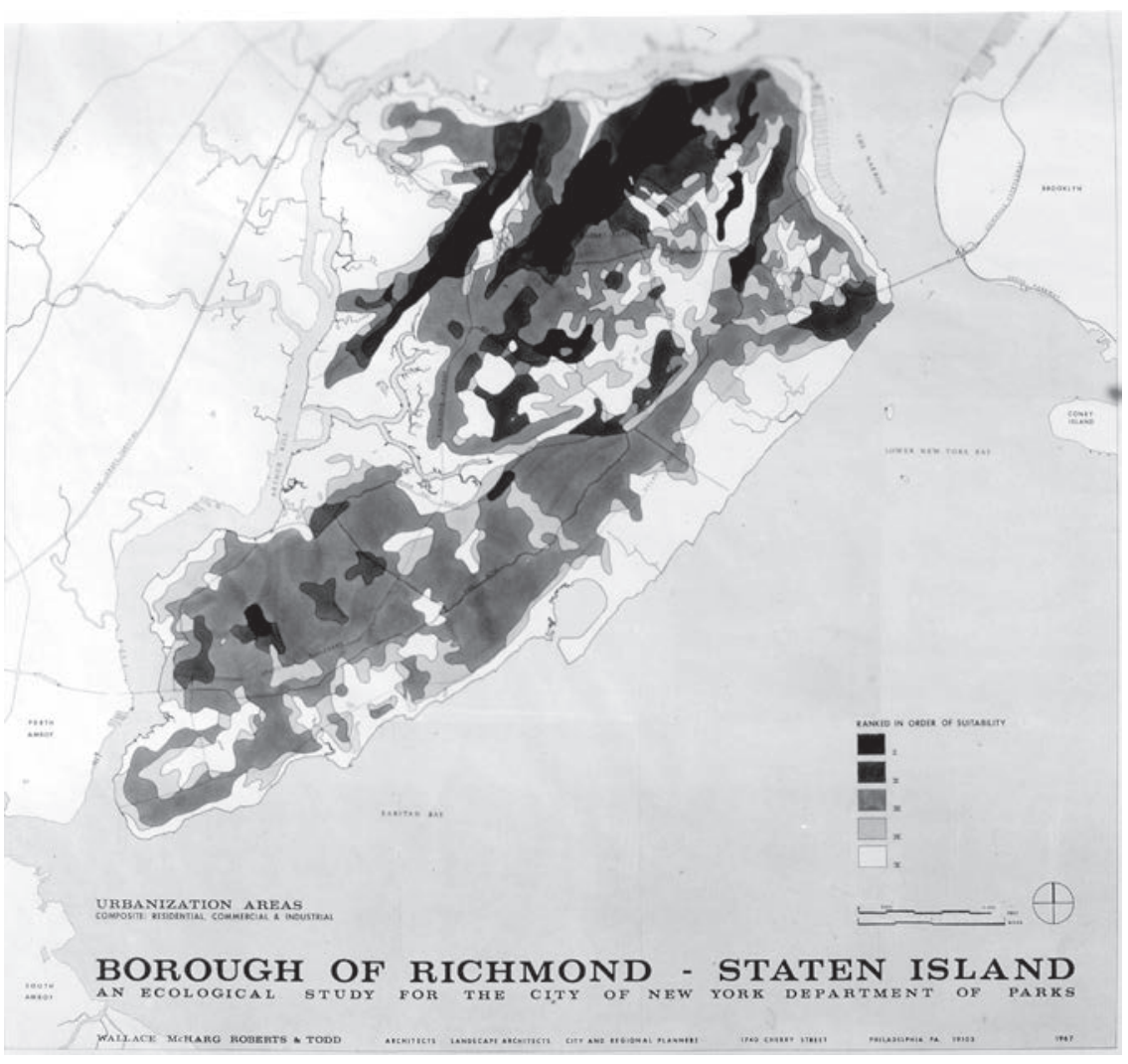

Figure 8

The landscape laid out in layers to discover relationships and identify possibilities for development on Staten Island in New York. This is a 1967 version of a suitability map for urbanization; from suitable (black) to not suitable (white). (Image: Ian L. McHarg Collection, The Architectural Archives, University of Pennsylvania.)
Models are abstract representations of relationships, variables, or units (e.g., urban or landscape models), and they serve as a foundation for building conceptual approaches for a design process.

- Design approaches that focus on context. These approaches regard the spatial-visual, geographic, ecological, social, or historical context as a foundation for further development. An understanding of the development in space and time (historical stratification, landscape biography) is important in this regard, as are spatial relationships and processes having to do with such aspects as soil conditions, hydrology, vegetation, and land division (e.g., layer approach) (Figure 8). One important concept in this design approach is that of genius loci: the tangible and intangible character of the place (Norberg-Schultz, 1980). Social-economic aspects and stakeholder involvement in spatial planning often play a central role as well (e.g., participatory design approaches) (Halprin, 1981) (Figure 9).
- Design approaches that focus on program. These approaches are of a functional or technical nature. In such methods, standards and indicators play important roles in design, focusing primarily on programs relating to recreation (e.g., green spaces at the neighborhood, community, district, or regional level), ecology (e.g., area size, corridor width, types of objectives) (Figure 10), the quantity and quality of water (e.g., water safety), agriculture (e.g., urban agriculture, land use), living and working, and vehicular traffic (e.g., noise standards, guidelines, capacity).

The choice of the RTD approach very much depends on the objective of the research or the questions posed. In practice, a specific approach used as a starting point of the inquiry may later be expanded to include aspects of other approaches. For example, in contextual approaches, programmatic aspects need to be considered but are not used as starting point. 


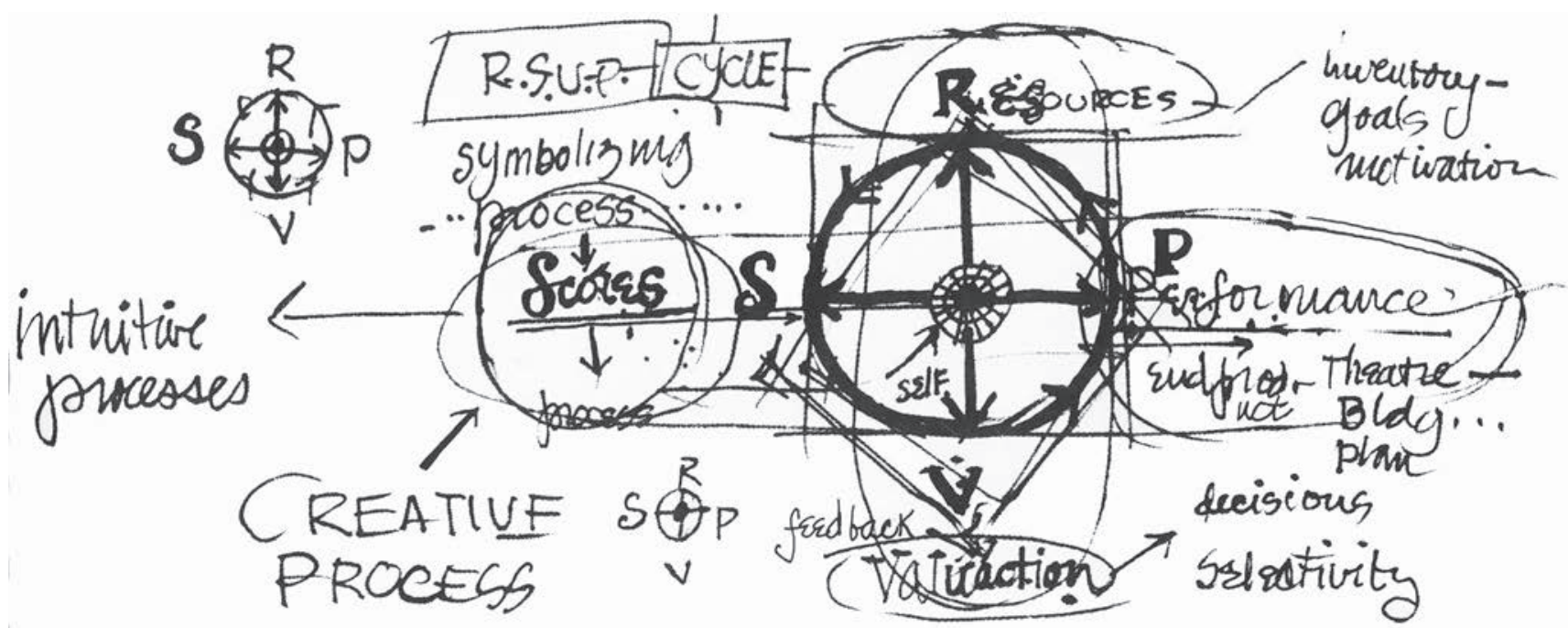

Figure 9

The RSVP cycle, a design method in which actors play a central role in a creative process. The procedure was sketched on a napkin by Lawrence Halprin around 1968. (Image: Lawrence Halprin Collection, The Architectural Archives, University of Pennsylvania.)
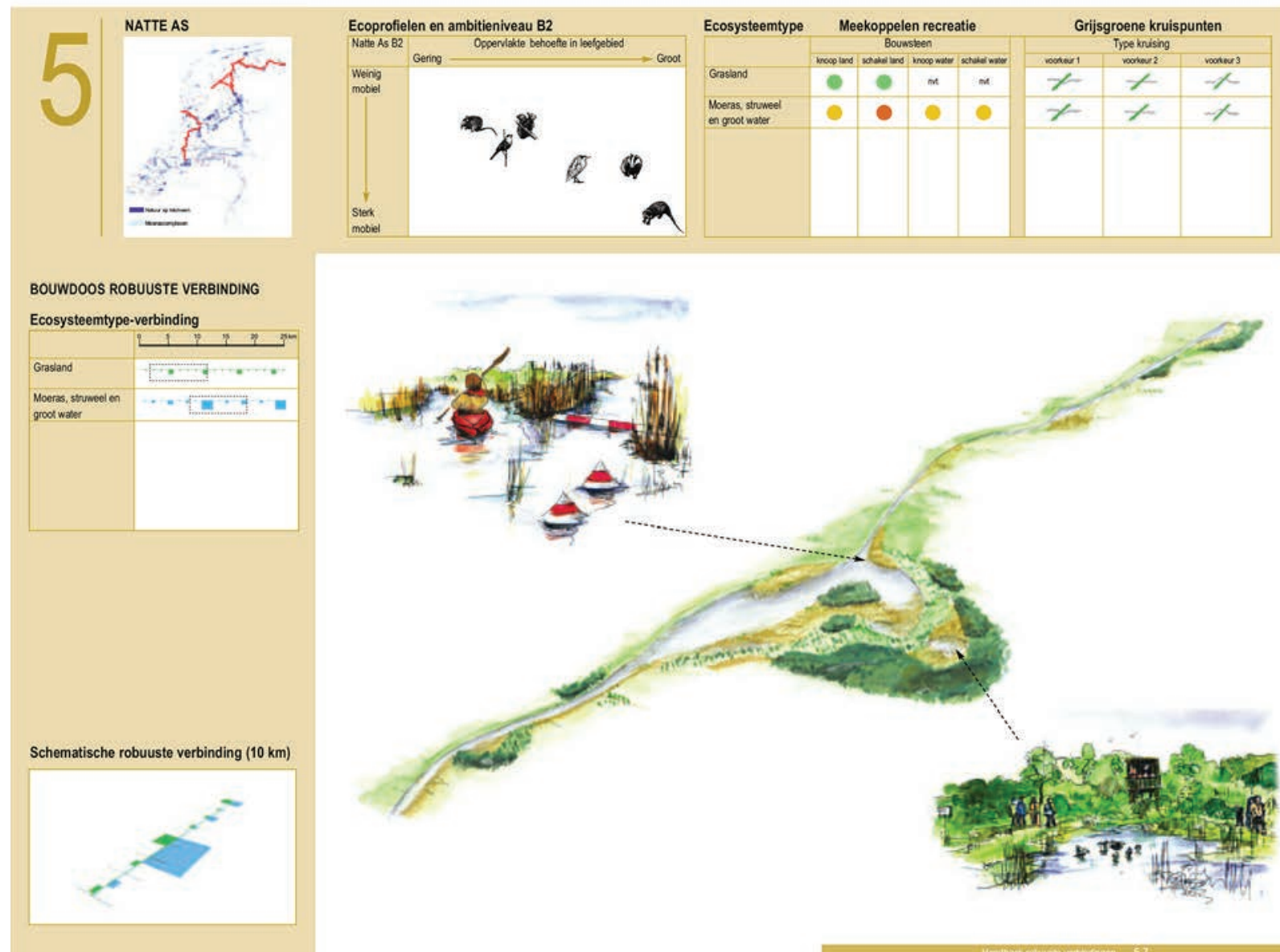

Figure 10

Design criteria for developing effective ecological corridors (Source: Broekmeyer \& Steingröver, 2001). 
Table 1. Types of knowledge in RTD.

\begin{tabular}{|c|c|c|}
\hline \multirow[t]{2}{*}{ Project-based } & Situational & $\begin{array}{l}\text { Engaging in deliberation concerning the legal, political, cultural, functional, economic and ecological context } \\
\text { of the design task. }\end{array}$ \\
\hline & Integrated & $\begin{array}{l}\text { Creating a synthesis of contradictory interests, changing restrictions and conflicting agendas while working } \\
\text { with various actors, applying diverse methods and operating in a variety of fields. }\end{array}$ \\
\hline \multirow[t]{2}{*}{ Form-based } & Visual & The development, fabrication, proposal and translation of ideas into words and images. \\
\hline & Material & $\begin{array}{l}\text { The assessment, exploration and realization of qualities of landscaping schemes and technical constructions, } \\
\text { in consideration of the aesthetic, functional and ecological consequences of design choices. }\end{array}$ \\
\hline \multirow[t]{2}{*}{ Idea-based } & Conceptual & $\begin{array}{l}\text { The production of ideas and proposals with space for poetic and speculative approaches that promote } \\
\text { imagination and unexpected proposals. }\end{array}$ \\
\hline & Strategic & $\begin{array}{l}\text { The assessment of the situation and the creation of future plans; the problem is structured and defined based } \\
\text { on the feasible solutions that have been proposed. }\end{array}$ \\
\hline
\end{tabular}

Adapted from Grocott, 2010.

\section{Types of Knowledge}

As argued, RTD can be a strategy for producing knowledge in different ways. This raises the question of what type of knowledge this could be. First, it is important to determine that the knowledge focuses on spatial issues. Spatial design integrates topics and interests and involves the operation of systems (e.g., the water system within the landscape or the urban vehicular traffic system) and their composition (the spatial structure, e.g., streets, roadways, and highways). RTD can also address the development of spatial prototypes (e.g., a city without cars) or metaphors, evaluate extreme scenarios to test the limits of the spatial system (e.g., what would an urban river delta landscape look like if the sea level rose by two meters?), or closely study a critical factor (e.g., the consequences of maximum dike-strengthening for a given landscape type) (Swaffield, 2016). Research intentions may focus on generating specific knowledge (i.e., specific design solutions in a specific context) or developing generic knowledge that could emanate from a meta-analysis of multiple studies. The results consist of design strategies, concepts, principles, or guidelines for research questions (Prominski, 2016). These questions can be overarching (what would a $\mathrm{CO}_{2}$-neutral city look like?), specific (how can a water-neutral garden be designed?), or thematic (what would a traffic-free street look like?). The tangible results can consist of an outline of ideas, an exemplary plan, or a technically feasible elaboration of a principle. This allows lessons to be learned at different levels, including (1) specific lessons relating to their application in the specific context of a place or area (what are the benefits?), and (2) generic lessons relating to the strategy, design concepts, and design principles for structure and implementation. As long as the landscape principles, urban planning context, culture of the users, and related aspects are comparable, the results are generalizable. Here meta-analysis is an important means for deriving specific understandings arising from evaluating various RTD results while having idiosyncratic design programs and temporal and spatial contexts.

As portrayed and described in Table 1, there are three knowledge types produced by RTD: project-based, form-based, or idea-based (Grocott, 2010). Project-based knowledge concerns the situation in its surroundings and the integrated solutions provided for it. Form-based knowledge involves visual communication and materialization of the design (i.e., how can it be created?). Idea-based knowledge consists of creative, intuitive, and speculative knowledge, as well as the structured knowledge that results in a strategy.

\section{CRITERIA FOR RTD}

When regarded as research inquiry, the design process must meet five criteria to ensure integrity and validity: purposefulness, reliability, consistency, 
transparency, and usability (Deming \& Swaffield, 2011; Groat \& Wang, 2013; Milburn et al., 2003; Yin, 2018). Purposefulness means what is being pursued (i.e., what problem should be solved) is clear. Developing a clear research objective, with questions for which answers must be identified, is an important condition for RTD. Thereafter, the design methods that could best help answer the questions can be selected.

For purposes of reliability, it is important for outcomes to be verifiable and testable. On which facts or arguments are the choices based? Are the results credible and intersubjective? For the first question, it must be clear which body of knowledge is applied by the researcher-designer. Figure 11 presents an overview of a body of knowledge that landscape architects can use for research. The latter question concerns whether the outcomes of the research are replicable and regarded as legitimate or valid by multiple individuals (subjects). This can be achieved by having the outcomes tested by external experts, colleagues with similar expertise, or local stakeholders with knowledge of the situation or place. For example, a landscape architect could evaluate an RTD project on a sustainable urban landscape development using performance indicators (e.g., LEED-ND sustainability metrics) or planning green-blue infrastructures that use effective design principles for cooling in urban context (e.g., REALCOOL design principles). In these cases, input and evaluation of experts such as ecologists or climatologists are inevitable. If the project concerns the use or experience of a place, it could and should be tested by residents and users.

Consistency concerns whether the underlying principles, considerations, and choices are applied and implemented in a constant manner; the working methods are characterized by stability and uniformity; and the study is logically constructed and meticulously implemented. Working systematically according to a method is very important in this regard.

Transparency concerns the question of whether the course of the RTD project is comprehensible. Can the process be repeated, are the research questions clear, and does the designer clearly explain how the research was conducted? Choices and outcomes should be explained explicitly and clearly in the design and accompanying notes.

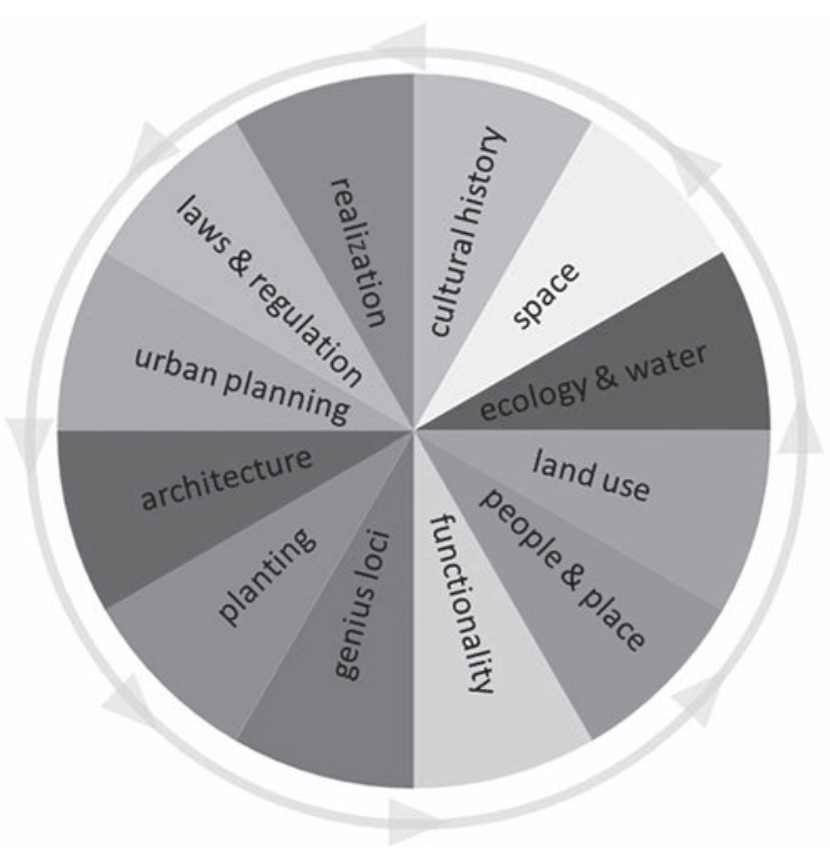

Figure 11

Scheme of the body of knowledge of landscape architecture. (Based on the competencies for landscape architecture defined in the further regulation of the Dutch Act Title of Architects.)

With regard to applicability, it is important for the outcomes of the research to be usable in practice. The knowledge that has been acquired should have tangible substance that can be implemented in a plan, project, or planning process. The knowledge must be specific or more broadly applicable to the solution of social issues. Although it could involve the solution to a specific design problem, outcomes are usually not exclusively applicable to any one situation or landscape. They form the foundation for design strategies, design principles, and design guidelines for other situations and comparable cities and landscapes.

\section{PLANNING AND IMPLEMENTING RTD}

How can RTD be applied in practice? Many design approaches are available and allow considerable leeway for quality requirement interpretation. Although there is no uniform recipe for planning and implementing RTD, there are several basic questions that must always be answered, and they can help provide direction and development to research using design:

- Objective: What is the problem or the objective of the study (the central question) 
and what questions (and subquestions) must be answered?

- Approach: Which design method or approach is best suited to achieving the objective? Which elements of design knowledge need to be applied? How can the process, considerations, choices, and dilemmas be documented?

- Instruments: What media and forms of representation should be used?

- Results: What are the design results, and to what extent are they usable and reliable? How are the results (or partial results) or solutions evaluated, and are the choices logical and traceable?

- Conclusions: What are the research outcomes (specific/generic) and how can they be transferred to other circumstances?

Although the questions presented here suggest a particular order, this is usually not the case in practice. For example, outlines can help one gain a grasp of the issue and identify factors and choices that play a role. Although one obviously has an idea in advance, designing around it can often improve the formulation of the objective and research questions, which must subsequently be answered. The research objective and related questions should be explicit and based on a relevant social issue that can be addressed with design expertise from a spatial designer. If the research is to be credible, it must be clear that the designer's expertise corresponds to the content of the research. In this regard, it is important to ensure that the drawing methods and the legend correspond to the objectives, so that the answers and solutions to the questions can be read from the representation. When designing alternative scenarios, it is important to use the same type of legend and representation method to preserve an overview of the differences.

\section{Peer Review and External Review}

To safeguard the purposefulness, reliability, consistency, transparency, and utility of an RTD project, collegial or mutual testing (peer review) is of crucial importance, and it is inseparably bound to RTD (Bowring, 1997; Armstrong, 1999; Milburn et al., 2003; KNAW, 2010). Peer review is a tried-and-tested method for improving, verifying, and validating the work quality by subjecting it to the critical view of expert peers, although others (e.g., specialists, experiential experts) can serve this in this function as well. These other parties are particularly important for research objectives involving specialized knowledge exceeding the competencies of the spatial designer. In design situations requiring specialized knowledge, the design should be tested by experts. For example, for ecological aspects, it would be advisable to commission ecologists to assess the quality of the habitats and ecological infrastructure that has been designed. Hydraulic engineers could assess the technical quality of flood defenses and hydraulic structures. The plausibility of the spatial organization of areas could be examined using feedback from local stakeholders (residents, users, and interest groups).

When answering the five questions above (from the objective to the conclusions), the content should be well documented in the form of text and make use of visual records: a logbook of drawings, scale models (or photographs of them), and diagrams. This is necessary to ensure the transparency of the process and clarify the choices. In visual thinking, outlines are often crucial to idea development. They are thus important materials that should be preserved. It is also important to describe the design process itself: which design approach was followed, and what steps were taken? It is advisable to document any dilemmas that arise in the course of the research project. Finally, it is essential to create clear design representations and report on the main points of feedback (from peers, experts, and stakeholders) that can involve quantitative and qualitative methods.

\section{CONCLUSION}

RTD can be regarded as a powerful research strategy in which complex spatial problems are approached in a creative and integrated manner. The targeted search plays a central role in a process in which thinking and producing go hand in hand. Mechanisms of research and design are combined with imagination, creativity, and innovation. In this respect, RTD is a way to understand where action, observation, and searching are used methodically to arrive at new insights. Such new insights or 
knowledge can take on a variety of forms, specific to a given location or more generic, but always practically applicable in some way. The results of RTD are not necessarily objective, but they must be characterized by integrity and validity. RTD is not about absolute truth finding but about practical feasibility and applicability.

Combining a spatial designer's expertise with a clear manner of exploring possibilities creates an element of intersubjectivity that is the foundation for general applicability. Although each designer creates unique spatial solutions, generally applicable principles can be derived from design experiments. These general understandings can be generated through idiosyncrasies of problem, space, and time, but it requires meta-analysis and generalization among multiple design explorations to establish concurrence from the multiple sets of findings. This is equivalent to generalizability that arises through multiple case study research, wherein meta-analysis of the cases allows for generalized understandings from the investigation of the design explorations. In this case, there must be some level of comparability among the designs to perform meta-analysis. In this perspective, the challenge for designer-researchers is to work in a manner that meets research requirements: it is targeted, reliable, consistent, transparent, and usable.

\section{REFERENCES}

Alexander, C., Ishikawa, S., \& Silverstein M. (1977). A pattern language: Towns, buildings, construction. Oxford University Press.

Armstrong, H. (1999). Design studios as research: An emerging paradigm for landscape architecture. Landscape Review, 5(2), 5-25.

Boeijen, A. van, Daalhuizen, J., Schoor, R. van der, \& Zijlstra, J. (2014). Delft design guide: Design strategies and methods. BIS.

Bowring, J. (1997). Research by design: The refereed studio. Landscape Review, 3(2), 54-55.

Broekmeyer, M. E. A., \& Steingröver, E. G. (2001). Handboek robuuste verbindingen. Alterra.

Carruth, S. (2015). Infrastructural urbanism that learns from place: Operationalising meta material practices to guide renewable energy planning in Greenland. Ph.D. diss., Aarhus School of Architecture.

Chenoweth, R., \& Chidister, M. (1983). Attitudes toward research in landscape architecture: A study of the discipline. Landscape Journal, 2(2), 98-113. https://doi.org/10.3368/ lj.2.2.98
Creswell, J. W. (2009). Research design: Qualitative, quantitative, and mixed method approaches. Sage.

Creswell, J. W., \& Creswell, J. D. (2018). Research design: Qualitative, quantitative, and mixed methods approaches (5th ed.). Sage.

Creswell, J. W., \& Plano Clark, V. L. (2018). Designing and conducting mixed methods research (3rd ed.). Sage.

Cross, N. (2007). Designerly ways of knowing. Birkhäuser.

de Jonge, J. (2009). Landscape architecture between politics and science: An integrative perspective on landscape planning and design in the network society. Blauwdruk. Retrieved from http://edepot.wur.nl/14357

Deming, M. E., \& Swaffield, S. (2011). Landscape architecture research: Inquiry, strategy, design. Wiley.

Foqué, R. (1975). Ontwerpsystemen: Een inleiding tot de ontwerptheorie. Spectrum.

Gibbons, M., Limoges, C., Nowotny, H., Schwartzman, S., \& Scott, P. (2012). The new production of knowledge: The dynamics of science and research in contemporary societies. Sage.

Glanville, R. (2015) The sometimes uncomfortable marriages of design and research. In: P. Rodgers, \& J. Yee, (Eds.) The Routledge companion to design research (pp. 9-22). Routledge.

Gobster, P. H., Nassauer, J. I., \& Nadenicek, D. J. (2010). Landscape journal and scholarship in landscape architecture: The next 25 years. Landscape Journal, 29(1), 52-57. https:// doi.org/10.3368/lj.29.1.52

Groat, L., \& Wang, D. (2013). Architectural research methods. Wiley.

Grocott, L. (2010). Design research \& reflective practice: The facility of design oriented research to translate practitioner insights into new understandings of design. Ph.D. diss., RMIT University.

Halprin, L. (1981). The RSVP cycles: Creative processes in the human environment. Braziller.

Hamel, R. (1990). Over het denken van de architect/On designing by architects: een cognitief psychologische beschrijving van het ontwerpproces bij architecten. AHA Books.

Jones, J. C. (1992). Design methods (2nd ed.). Van Nostrand Reinhold.

Kalay, Y. (2004). Architecture's new media: Principles, theories, and methods of computer-aided design. MIT Press.

Klaasen, I. T. (2004). Knowledge-based design: Developing urban and regional design into a science. Delft University Press.

KNAW. (2010). Quality assessment in the design and engineering disciplines. A systematic framework. Royal Netherlands Academy of Arts and Sciences.

LaGro, J. A. Jr. (1999). Research capacity: A matter of semantics? Landscape Journal, 18(2), 179-186. https://doi.org/10.3368/ lj.18.2.179

Lawson, B. (2008). How designers think. The design process demystified. Architectural Press.

Lee, L. (2011). An integrated design strategy for South Australia. Adelaide Thinkers in Residence. 
Lenzholzer, S., Duchhart, I., \& van den Brink, A. (2017). The relationship between research and design. In $A$. van den Brink, D. Bruns, H. Tobi, \& S. Bell (Eds.), Research in landscape architecture: Methods and methodology (pp. 54-64). Routledge.

Lenzholzer, S., Nijhuis, S., \& Cortesao, J. (2018). RTD in landscape architecture: A first state of the art. Peer Reviewed Proceedings Design Research Society, 1-13.

Magnani, L. (2001). Abduction, reason, and science: Processes of discovery and explanation. Springer.

Martin, B., \& Hanington, B. (2012). Universele ontwerpmethoden: 100 manieren voor het onderzoeken van complexe problemen, het ontwikkelen van innovatieve ideeën en het ontwerpen van effectieve oplossingen. BIS.

McHarg, I. L. (1969). Design with nature. Natural History Press.

Milburn, L. S., \& Brown, R. D. (2003). The relationship between research and design in landscape architecture. Landscape and Urban Planning, 64, 47-66. https://doi.org/10.1016/ S0169-2046(02)00200-1

Milburn, L. S., Brown, R. D., Mulley, S. J., \& Hilts, S. G. (2003). Assessing academic contributions in landscape architecture. Landscape and Urban Planning, 64, 119-129. https://doi. org/10.1016/S0169-2046(02)00204-9

Milburn, L. S., Brown, R. D., \& Paine, C. (2001). “. . . Research on research": Research attitudes and behaviors of landscape architecture faculty in North America. Landscape and Urban Planning, 57, 57-67. https://doi.org/10.1016/ S0169-2046(01)00188-8

Murphy, M. (2016). Landscape architecture theory. Island Press.

Nassauer, J. I., \& Opdam, P. (2008). Design in science: Extending the landscape ecology paradigm. Landscape Ecology, 23, 633-644. https://doi.org/10.1007/s10980-008-9226-7

Nijhuis, S. (2013). New tools: Digital media in landscape architecture. In J. Vlug et al. (Ed.), The need for design (pp. 86-97). Van Hall Larenstein.

Nijhuis, S. (2015). GIS-based landscape design research: Stourhead landscape garden as a case study. A+BE. https://doi. org/10.7480/abe.2015.13

Nijhuis, S., \& Bobbink, I. (2012). Design related research in landscape architecture. Journal of Design Research, 10(4), 239-257. https://doi.org/10.1504/JDR.2012.051172

Norberg-Schulz, C. (1980). Genius loci: Towards a phenomenology of architecture. Rizzoli.

Nowotny, H., Scott, P., \& Gibbons, M. T. (2013). Re-thinking science: Knowledge and the public in an age of uncertainty. Wiley.

Pierce, C. (1955). Abduction and induction. In J. Buchler (Ed.), Philosophical writings of Pierce (pp. 150-156). Dover Publications.

Prominski, M. (2016). Design guidelines. In A. van den Brink, D. Bruns, H. Tobi, \& S. Bell (Eds.), Research in landscape architecture: Methods and methodology (pp. 194-207). Routledge.

Rittel, H., \& Webber, M. (1973). Dilemmas in a general theory of planning. Policy Sciences, 4(2), 155-169.
Robinson, K. (2013). Buiten de lijntjes: Stimuleer je creativiteit. Spectrum.

Roozenburg, N. F., \& Eekels, J. (1996). Product design: Fundamentals and methods. Wiley.

Rowe, P. G. (1998). Design thinking. MIT Press.

Schön, D. (1983). The reflective practitioner: How professionals think in action. Basic Books.

Simon, H. (1981). The sciences of the artificial (2nd ed.). MIT Press.

Steenbergen, C. M., Meeks, S., \& Nijhuis, S. (2008). Composing landscapes: Analysis, typology and experiments for design. Birkhäuser.

Steenbergen, C. M., Mihl, H., \& Reh, W. (2002). Introduction: Design research, research by design. In C. M. Steenbergen, H. Mihl, W. Reh, \& F. Aerts (Eds.), Architectural design and composition (pp. 12-25). Bussum: Thoth.

Steinitz, C. (1990). A framework for theory applicable to the education of landscape architects (and other environmental design professionals). Landscape Journal, 9(2), 136-143. https://doi.org/10.3368/lj.9.2.136

Steinitz, C. (1995). Design is a verb, design is a noun. Landscape Journal, 14(2), 188-200. https://doi.org/10.3368/ lj.14.2.188

Steinitz, C. (2012). A framework for geodesign: Changing geography by design. ESRI Press.

Swaffield, S. (2016). Case studies. In A. van den Brink, D. Bruns, H. Tobi, \& S. Bell (Eds.), Research in landscape architecture: Methods and methodology (pp. 105-119). Routledge.

Thering, S., \& Chanse, S. (2011). The scholarship of transdisciplinary action research: Toward a new paradigm for the planning and design professions. Landscape Journal, 30(1), 6-18. https://doi.org/10.3368/lj.30.1.6

van den Brink, A. \& Bruns, D. (2014) Strategies for enhancing landscape architecture research, Landscape Research, 39:1, 7-20, https://doi.org/10.1080/01426397.2012.711129

van den Brink, A., Bruns, D., Tobi, H., \& Bell, S. (2017). Research in landscape architecture: Methods and methodology. Routledge.

Van Schilfgaarde, P. (1970). Het kennisbegrip in wetenschap en beroep: Objectiviteit als pretentie. Samsom.

Verschuren, P. (2007). De probleemstelling voor een onderzoek. Het Spectrum.

Von Seggern, H., Werner, J., \& Grosse-Bächle, L. (2008). Creating knowledge: Innovationsstrategien im Entwerfen urbaner Landschaften = innovation strategies for designing urban landscapes. Jovis.

Westrik, J., \& Büchi, H. (1989). Stedebouwkundige ontwerpmethoden. Publikatieburo, Faculteit der Bouwkunde, Technische Universiteit.

Yin, R. K. (2018). Case study research: Design and methods (6th ed.). Sage.

Zeisel, J. (1981). Inquiry by design: Tools for environment-behavior research. Cambridge University Press. 
AUTHOR CONTRIBUTION Steffen Nijhuis is the main author and conceived, structured, and developed most of the content of the paper. Jeroen de Vries contributed by refining the manuscript and elaborating on the types of knowledge generated by RTD.

ACKNOWLEDGMENTS The authors thank the reviewers and editorial team for their constructive comments and help.

AUTHORS Dr. Steffen Nijhuis is Head of Landscape Architecture Research, Director European Post-master in Urbanism (EMU), and Associate Professor at the Faculty of Architecture and the Built Environment, Delft University of Technology (The Netherlands). He is an award-winning academic and experienced landscape architect and acts as an adviser to international governmental/regional authorities and nongovernmental organizations. Currently he leads research projects that address landscape-based urban development and watersensitive and socioecologically inclusive urbanism. He is the author of numerous academic publications and has been a frequent visiting professor/guest lecturer at universities throughout Europe, Asia, and North America. www.steffennijhuis.nl
Jeroen de Vries is a landscape architect with a specialization in landscape design and landscape ecology, with a personal mission to foster quality of outdoor space by promoting sustainability and ecological quality. $\mathrm{He}$ is partner at the DG Groep for drawing up strategic and management plans for green areas and final designs. He was formerly a teacher/researcher at VHL University in the research group Design for Local Food. He is currently a director researcher at the LE:NOTRE Institute in Wageningen.

PEER REVIEW STATEMENT This submission was peer-reviewed by four reviewers selected by the Editorial Office. Their contributions are gratefully acknowledged and appreciated. 